\title{
COMPARACIÓN DE LOS RESULTADOS DEL BALANCE SOCIAL COMO HERRAMIENTA DE GESTIÓN: LOS CASOS DE CACEC Y CHIBULEO
}

\author{
COMPARISON OF THE RESULTS OF THE SOCIAL BALANCE SHEET AS A MANAGE- \\ MENT TOOL: THE CASES OF CACEC AND CHIBULEO
}

\section{RESUMEN}

El cooperativismo a pesar de ser muy antiguo es adaptativo y ofrece un universo de posibilidades. En el caso de Ecuador, las cooperativas han ido liderando buena parte del sector de ahorro y crédito hasta verse multiplicadas a través de la aparición de nuevas organizaciones, funcionalidades y servicios. En un ejercicio de control público a las cooperativas, la Superintendencia de la Economía Popular y Solidaria, ha impuesto diferentes obligaciones entre las que destacan la de elaborar un Balance Social. Su implementación ha provocado el desarrollo de diferentes herramientas y disparidad de análisis. En este contexto, se examinan los resultados de la aplicación del Balance Social en las cooperativas CACEC y Chibuleo. Se realiza un estudio de caso analizando sus incoherencias y funcionalidades en fases como: análisis de información; evaluación del desempeño de la misión cooperativa en relación a sus procesos de responsabilidad social y elaboración de indicadores para cada principio cooperativo. Se llega a la conclusión de que el sistema de indicadores tiene capacidad suficiente para evaluar en qué medida la institución financiera cumple con su misión y mostrar el grado de correlación con los resultados obtenidos, una vez aplicados los correspondientes planes correctivos.

Palabras clave: Balance social, cooperativismo, responsabilidad social, indicadores.

\section{ABSTRACT}

Despite being very ancient, cooperativism is adaptative and submits such a world of possibilities. Within Ecuadorian instance, credit unions have headed great portion of the savings and credit area reaching to spreading by coming into sight new organizations, functionalities and services. Performing public control activities over credit unions, the Popular and Solidarity Economy Superintendence has set different requirements to meet, among which the elaboration of a Social Balance. Its implementation has led to growth of different tools and discrepancy among analysis. In this context, Social Balance application results on CACEC and Chibuleo credit unions are examined. A case study is carried out, analysing its contradictions and functionalities in phases like: information analysis; performance assessment to cooperative mission in relation to its social responsibility processes and indicators making for each cooperative premise. It is concluded that the indicators'system is capable enough to assess to what extent the financial institution fulfills its mission and to show the correlation level by the results gotten once the corrective plans have been implemented.

Keywords: Cooperativism, indicators, social balance, social responsibility.
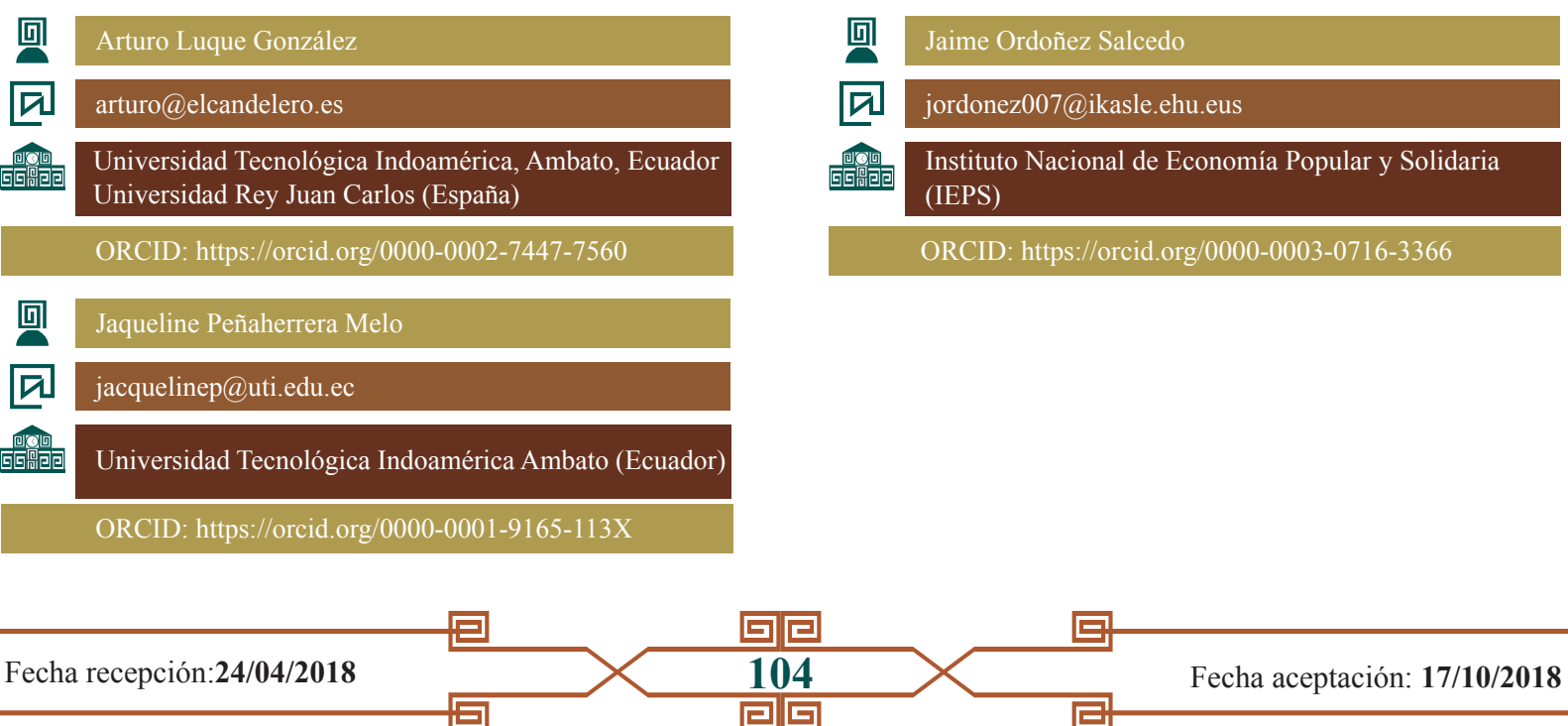


\section{INTRODUCCIÓN}

En Ecuador existen 617 entidades activas del sector financiero popular y solidario. De éstas, 612 son cooperativas de ahorro y crédito, 4 asociaciones mutualistas de ahorro y crédito y una caja central (Pazos, Guamaní \& Égüez 2018). Addemás, Ecuador se constituye como el segundo país por número de cooperativas en Latinoamérica después de Brasil. Sus integrantes suman más de 4.700 .000 socios alcanzando una cifra en activos de 8.300 millones de dólares (Superintendencia de Economía Popular y Solidaria SEPS $2018 b$ ). El 66\% del microcrédito ofertado en Ecuador lo otorga el sistema cooperativo, lo que convierte a este producto financiero en su distintivo frente a la banca tradicional. En los últimos tres años y medio, a nivel global $\mathrm{y}$ en concreto en Ecuador, el sector creció ostensiblemente, de hecho, en el artículo: Las cooperativas crecen y se adaptan a nuevas regulaciones ( 7 de junio de 2015) de la revista Líderes, el gerente de la Cooperativa 29 de Octubre, Gonzalo Vivero, indica que el sector cooperativo financiero alcanzó el $17 \%$, mientras que la banca privada llegó al $6 \%$, lo que pone de manifiesto el empuje económico del sector. Para la Organización Internacional del Trabajo (OIT 2018):

Las cooperativas no sólo son importantes como medio para mejorar las condiciones de vida y de trabajo de mujeres y hombres en todo el mundo, sino que también ponen a dispo- sición de los usuarios infraestructura y servicios esenciales, incluso en áreas olvidadas por el Estado y las empresas inversoras. Las cooperativas tienen una probada trayectoria en materia de creación y mantenimiento del empleo, ya que actualmente brindan más de 100 millones de puestos de trabajo. Asimismo, contribuyen al avance del Programa Global de Empleo de la OIT y a la promoción del trabajo decente.

En Ecuador las cooperativas de ahorro y crédito están segmentadas conforme a lo dispuesto en el Art. 14, numeral 35 del Código Orgánico Monetario y Financiero, que señala, entre las funciones de la Junta de Política y Regulación Monetaria y Financiera, "Establecer la segmentación de las entidades del Sector Financiero Popular y Solidario". Por lo que expide la resolución No. 038-2015-F, el 13 de febrero de 2015 que fija la norma para la segmentación de las entidades del sector financiero popular y solidario según sus activos. Además, la regulación determina la tipificación de los créditos, la creación de un seguro de depósitos y de un fondo de liquidez. En la tabla 1, se muestra el monto de activos de acuerdo al cual, una cooperativa de ahorro y crédito es ubicada en uno u otro segmento de acuerdo lo que se aplican diferentes normas como la de prevención y riesgos. A priori, los requerimientos implementados en las cooperativas tienen la finalidad de generar certidumbre y evitar fraudes.

Tabla 1. Distribución

SEGMENTACIÓN DE COOPERATIVAS DE AHORRO Y CRÉDITO EN ECUADOR

\begin{tabular}{lcl}
\hline SEGMENTOS & COACS & \multicolumn{1}{c}{ ACTIVOS (USD) } \\
\hline Segmento $1^{1}$ & 27 & Mayor a $80^{\prime} 000.000,00$ \\
\hline Segmento 2 & 38 & Mayor a 20'000.000,00 hasta $80^{\prime} 000.000,00$ \\
\hline Segmento 3 & 82 & Mayor a 5'000.000,00 hasta 20'000.000,00 \\
\hline Segmento 4 & 181 & Mayor a 1'000.000,00 hasta 5'000.000,00 \\
\hline Segmento 5 & 340 & Hasta 1'000.000,00 \\
& Cajas de Ahorro, bancos comunales y cajas comunales
\end{tabular}

Total:

668

Fuente: (Superintedencia de Economía Social y Solidaria 2017) Para el Segmento uno, no se considera la Corporación Nacional de Finanzas Populares y Solidarias - CONAFIPS 
Dentro de esta panorámica la Ley Orgánica de la Economía Popular y Solidaria (LOEPS) de Ecuador, además de tomar como propio lo dictaminado por la Alianza Cooperativa Internacional (ACI), en su Segunda Disposición establece la obligatoriedad de incorporar en sus informes el balance social con el fin de analizar el alineamiento de los principios cooperativos con los objetivos sociales (y por ende éticos que cada vez más la sociedad demanda). Partiendo de lo anteriormente señalado se establece la necesidad de analizar los resultados del balance social como herramienta de gestión en dos casos como son CACEC (Latacunga) y Chibuleo (Ambato) con el fin de evaluar la proposición de indicadores seleccionados en sus respectivos balances y la efectividad en la implementación de los mismos no solo como herramienta normativa, sino también de mejora continua.

\section{Marco conceptual}

Los tiempos cambian y las organizaciones también. El sector cooperativo está influido por la lógica evolución de los tiempos, así como por nuevas necesidades de usuarios, clientes y socios. Las transformaciones económicas actuales deben promover su adaptación a los cambios sociales y medioambientales existentes (Mathiyazhagan, Govindan, NoorulHaq \& Geng 2013; Ocampo, Perdomo-Ortiz \& Castaño 2014).

Sheldon (1923) señala los años 20 como punto de partida en la gestión empresarial con una clara relación entre la gestión propiamente dicha y los aspectos sociales. Las organizaciones deben estar contextualizadas en relación a las necesidades de las comunidades sociales (Schlusberg 1969) con el fin de mejorar la sociedad con la que se interrelacionan (Fernández, Geba, Montes \& Schaposnik 1998). Las cooperativas deben promover la vinculación necesaria entre empresas, sindicatos y Estados con el fin de coexistir de manera harmónica con todos los grupos de interés con los que interactúan ejerciendo un claro papel protagonista dentro de su dimensión social y medioambiental (Lucena, Freitez \& Hernández 2007). Ser responsable como organización es consustancial a los orígenes cooperativos, forma parte de su misión, de su idiosincrasia, debiéndose proyectar como medio y no como fin (Bastidas-Delgado 2007).

Cabe la necesidad de evitar réplicas de modelos entre el sector cooperativo de ahorro y crédito y otros sistemas como el bancario, más allá de tener elementos comunes destacables en ambos sectores como sostenibilidad, competitividad y eficiencia ya que ni tienen los mismos orígenes ni los mismos fines.

Entre muchas de las medidas propuestas por el sector cooperativo destaca aquel que se basa en sus principios cooperativos según Cooperativas de las Américas ACI (2018) membresía abierta y voluntaria, destacando que las cooperativas son organizaciones voluntarias abiertas, 2) control democrático de los miembros, mediante participación activa y mismos derechos sin discriminación, 3) participación económica de los miembros, siendo por lo menos una parte de ese capital es propiedad común de la cooperativa siendo una parte indivisible, 4) autonomía e independencia, siendo organizaciones autónomas de ayuda mutua, 5) educación, formación e información, 6) cooperación entre cooperativas, sirviendo a sus miembros con la finalidad de fortalecer el movimiento cooperativo trabajando de manera conjunta por medio de estructuras locales, nacionales, regionales e internacionales y 7) compromiso con la comunidad, fomentando el desarrollo sostenible de su comunidad por medio de políticas aceptadas por sus miembros.

\section{La economía social}

La economía popular y solidaria (EPS) se basa en relaciones de solidaridad, cooperación y reciprocidad primando al ser humano como elemento de coexistencia. Se tiene especial interés por las comunidades adyacentes y su relación con la naturaleza. Las organizaciones creadas bajo el paraguas de este precepto basan su leit motiv en la satisfacción de las necesidades de sus miembros por encima de los procesos de acumulación de capital (Páez 2013). La estimación de estos fundamentos requiere de una metodología que trascienda del ámbito económico habitual como es el Balance Social. Para la SEPS (2018a:1) 
El Balance Social reúne y sistematiza la información de áreas como la medioambiental, económica y social. Todo ello en un documento público donde se cuanti-cualifican lo datos a través de instrumentos como los indicadores (numéricos o no, binarios, de profundidad, etc.) que tratan de medir la actividad de la entidad en relación y con referencia a sus principios y valores $[. .$.

Según la Ley de Economía Popular y Solidaria y del Sistema Financiero Popular y Solidario (2011), las organizaciones de la EPS deben incluir el Balance Social como parte de sus informes de gestión para evidenciar el nivel de cumplimiento de los principios y sus objetivos sociales, en cuanto a la preservación de su identidad, su incidencia en el desarrollo social y comunitario, impacto ambiental, educativo y cultural. El Balance Social ofrece información de carácter interno y externo conociéndose a través de él la aplicación o no de los principios cooperativos y las metas sociales (Fernández et al. 1998). Es un instrumento de gestión que tiene la finalidad de planear, organizar, dirigir, registrar, controlar y evaluar en términos cuantitativos y cualitativos la cooperativa (Nevado 1999). Una de las finalidades es dotar de objetividad a criterios subjetivos, en muchos casos basados en ideales, principios, deseos, etc., apoyándose para su elaboración en juicios comparativos y categóricos (León et al. 2011) con el fin de analizar de manera sistemática el impacto social de las cooperativas (Martínez \& Bialakowsky 1984) así como sus elementos favorables y desfavorables.

Según la figura 1: Distribución, se muestra de manera cartografiada el número de cooperativas en Ecuador a nivel provincial observándose su alta concentración en tres provincias como Azuay, Tungurahua y Pichincha además del nivel de segmentación al que pertenecen las mismas.

\section{Figura 1. Distribución}

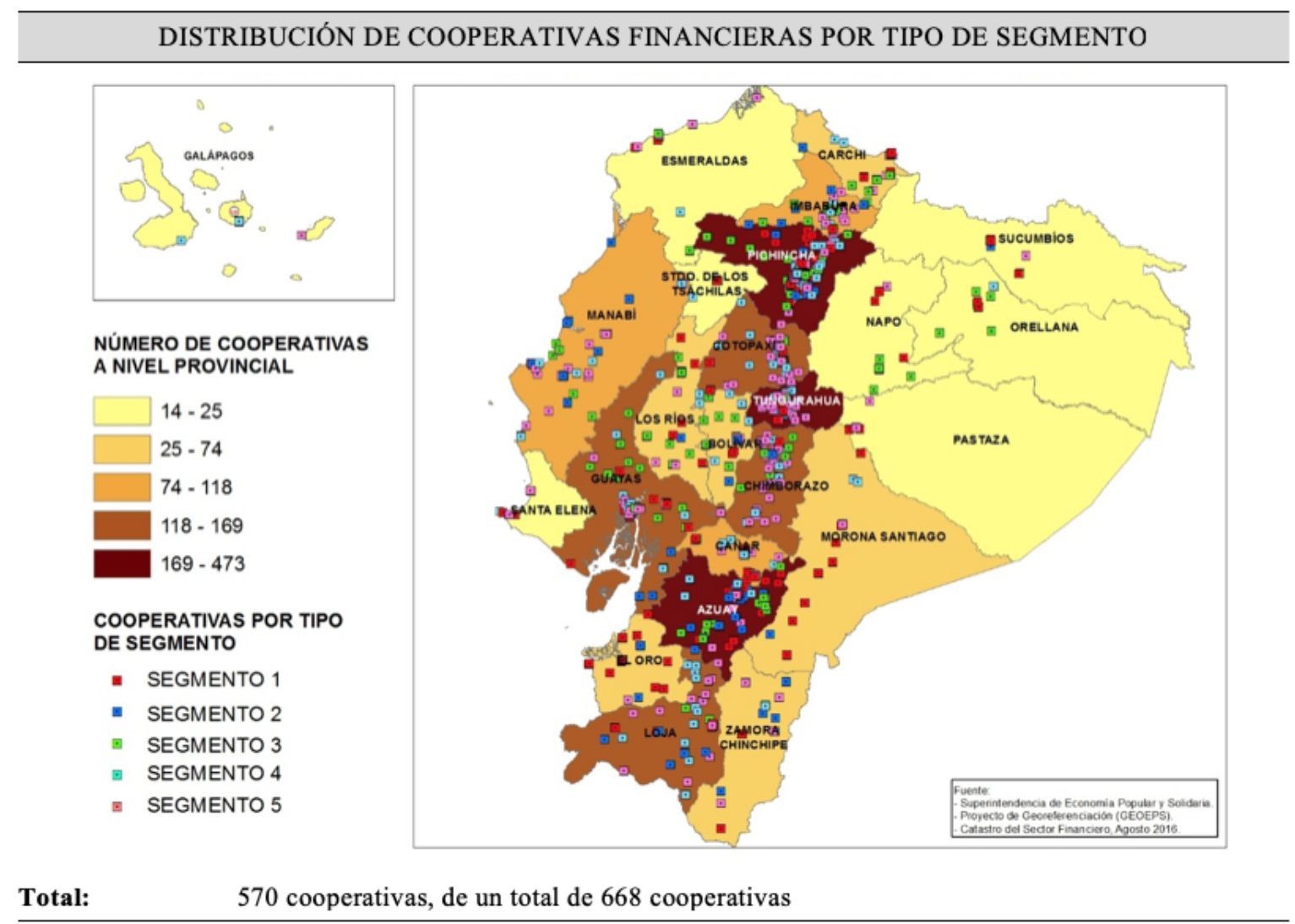

Fuente: Superintendencia de Economía Popular y Solidaria. 


\section{Balance Social Cooperativo}

La propuesta cooperativa, combina armoniosamente lo económico y lo social a través de prácticas empresariales y asociativas bajo el precepto de que "la empresa está supeditada a la asociación" considerando finalmente a la gestión empresarial como el medio óptimo para la consecución de sus fines sociales (Vásquez 2013). Esta naturaleza de empresa social genera la permanente búsqueda de herramientas con el fin de facilitar su gestión desde un punto de vista más democrático desarrollando un perfil más humano. El Balance Social Cooperativo según González y San Bartolomé (2008:34)

Aparece como una herramienta de la gestión socioeconómica que permite a las cooperativas medirse y mostrar su eficiencia a los asociados dueños especialmente y a todos los demás grupos de interés que están impactando por su accionar en relación con el cumplimiento de su propia esencia o identidad, es decir los valores y principios cooperativos.

La Superintendencia de Economía Popular y Solidaria, órgano supervisor de las cooperativas de ahorro en Ecuador, explora y construye de manera continua parámetros "óptimos" con el fin de medir y regular la gestión cooperativa. Según Montes (2016:206) el Balance Social:

Tiene la doble finalidad de reflejar la identidad cooperativa (a través del cumplimiento de los Principios Cooperativos), y el ejercicio de la responsabilidad social asumida por la cooperativa. Hace posible la comparación entre distintas cooperativas, dado que los Principios son comunes, y permite que cada una realice su autoevaluación, en tanto fija y mide el cumplimiento de sus programas sociales.

\section{METODOLOGÍA}

Se parte de la necesidad de conceptualizar y delimitar los requerimientos por parte del Estado en el sector cooperativo. Para ello se realiza una revisión previa de carácter normativo, político y social (White 1992) con la finalidad de resolver el alcance e implicación de las políticas que regulan el sector e influyen en él. El estudio se basa en el análisis de cada uno de los grupos de interés en relación a indicadores como elementos necesarios para adentrarse en la regulación y supervisión en las cooperativas de ahorro y crédito (Arzbach, Durán \& Báez 2010).

La investigación realizada es principalmente de corte cualitativo, se busca contextualizar la medición del balance social en realidades idénticas, analizando de manera crítica y propositiva el sector de las cooperativas de ahorro y crédito como son las dos cooperativas analizadas.

\section{Cooperativa de ahorro y crédito Chibuleo Ltda.}

La Cooperativa de Ahorro y Crédito Chibuleo Ltda. (2018), cumplió el 17 de enero de 201815 años de vida. Tiene 123.000 socios y cuenta con 8 oficinas operativas. Sus activos superan los 134 millones de dólares (Superintendencia de Economía Popular y Solidaria 2019). Es una institución ubicada dentro del segmento 2, aunque de acuerdo a la clasificación de cooperativas financieras realizada por la SEPS, debe constar en el segmento 1. En su declaratoria de Misión señala ser:

Una Cooperativa de Ahorro y Crédito que brinda oportunidades a nuestros socios y clientes en el sector de la economía popular y solidaria, a través de servicios financieros con enfoque de calidad, oportunidad y rentabilidad financiera y social, comprometidos con el desarrollo socioeconómico de nuestra zona de influencia. 
Manifiesta con claridad el nivel de importancia que tiene en su gestión, el componente social, declarándolo como un indicador de rentabilidad. Yumisaca y Coba (2017), proponen en su estudio sobre responsabilidad social en el marco de los principios del cooperativismo

diseñar un modelo de responsabilidad social como herramienta para el cumplimiento de los principios del Cooperativismo en la Cooperativa de Ahorro y Crédito Chibuleo Ltda. empleando la herramienta de Balance Social como instrumento de ponderación.

\section{Cooperativa de Ahorro y Crédito de Edu- cadores de Cotopaxi "CACEC" Ltda.}

Como muchas organizaciones cooperativas, CACEC, nace con la intención de satisfacer las necesidades de crédito de un grupo social, en este caso los educadores de la provincia de Cotopaxi. La Cooperativa de Ahorro y Crédito de Educadores de Cotopaxi CACEC Ltda. (2018b) se crea mediante Acuerdo Ministerial No. 4439 del 15 de julio de 1965. Según la segmentación de la SEPS, la cooperativa está circunscrita al segmento 3 por su monto de activos que no supera los 20 millones de dólares (CACEC 2018a). De acuerdo con su misión:

\begin{abstract}
Busca reivindicar a la empresa en la sociedad como un ente digno de confianza, generando riqueza a partir de un trabajo holístico, incentivando a los colaboradores la preparación constante, y de esta manera generar seguridad financiera en la comunidad, compartiendo la riqueza con el cliente interno, externo y comunidad, dando prioridad al saber hacer antes de hacer sin saber, y de esta manera satisfacer las necesidades de nuestros socios y/o clientes.
\end{abstract}

En esta declaratoria de intenciones, los indicadores de cumplimiento se relacionan de forma directa con el cliente interno para fines principalmente económicos. A partir de este análisis Mullo y Coba (2018) evalúan la factibilidad de la aplicación de los planes de acción para optimizar la Responsabilidad Social Empresarial ponderada a través del Balance Social para mejorar el financiamiento de la Cooperativa de Ahorro y Crédito Cacec Ltda.

La metodología se estructura en tres fases que se describen a continuación.

\section{Levantamiento de la información en los casos.}

Los datos corresponden a las cooperativas de ahorro y crédito Cacec y Chibuleo, fueron obtenidos entre junio y septiembre de 2016 con la finalidad de definir indicadores (Marradi, Archenti \& Piovani 2007) y analizar mediante ellos, la aplicación del Balance Social como herramienta de gestión en relación al objeto de la misión de la propia cooperativa.

Para cuantificar los indicadores se recurre a información secundaria de las cooperativas. Estos se obtienen a través de un análisis documental (Abela 2002) además de encuestas a socios a una muestra de la población total (Castro \& Hinestroza 2000). En Chibuelo Ltda., se considera como población a 4.517 socios que corresponden a la matriz; mientras que CACEC Ltda., la población asciende a 1.900 socios que es total de la cooperativa. Con un error estadístico de 5 $\%$ y aplicando la muestra de universo finito se obtiene como tamaño de la muestra a 151 socios en el primer caso y 86 socios en el segundo (Arias 2012).

Con la información ya levantada, se aplicó la guía metodológica de la Confederación Alemana de Cooperativas DGRV (2010) la cual determina la importancia de los indicadores respecto del cumplimiento de la misión institucional. Para ello establece una escala valorativa entre 1 y 3 . Por tanto, el promedio de los indicadores de la dimensión que más de aleje del valor máximo (3) demanda (de los gestores) planes de acción correctivos. DGRV recomienda 3 valores en relación a los indicadores de las dimensiones del Balance Social: 1) no afectación al cumplimiento de la misión, 2) importancia para el cumplimiento de la misión y 3) necesidad 
para el cumplimiento de la misión.

Finalmente, con la aplicación de esta metodología se obtiene información para la planificación correctiva de los indicadores.

\section{Construcción de tablas.}

Los predictores creados a partir de la información levantada, se relacionan de manera inexorable con los procesos de responsabilidad social en base a tres dimensiones como son: social, económica y medioambiental, así como sus interrelaciones generadas. Con estos elementos se construyen tablas en las que se presentan los indicadores del balance social y la importancia de los mismos en relación al cumplimiento de su misión expresados en valores de 1 a 3 . Así también se construye una figura en forma de "telaraña" en base a los valores promedios ponderados con la finalidad de observar y posteriormente analizar las diferencias de los resultados obtenidos en las cooperativas de estudio.

\section{Análisis comparativo.}

Se analiza la aplicación del Balance Social Cooperativo como herramienta de ponderación de Responsabilidad Social en dos organizaciones de la EPS dedicadas a la intermediación financiera a través del proceso de comparación (Durkheim 1997; Sartori \& Morlino 1999; Ramos 2017) teniendo presente que las cooperativas analizadas pertenecen a diferentes segmentos, con misiones y estrategias no siempre coincidentes. El objetivo consiste en evaluar los resultados de los indicadores del Balance Social Cooperativo analizando cómo esta herramienta apoya las estrategias y planes para la consecución de objetivos institucionales en todas sus dimensiones.

\section{RESULTADOS Y DISCUSIÓN}

Para lograr la comparación de resultados se parte de aplicar el modelo de Balance Social Cooperativo de acuerdo con la propuesta de la Alianza Cooperativa Internacional donde las dimensiones son los principios cooperativos. Los indicadores construidos proporcionan información socioeconómica básica que se desprende de los datos de las organizaciones (Montes 2016). En la tabla 2, se muestran los indicadores que miden la construcción del Balance Social en las Cooperativas Chibuleo Ltda., y CACEC Ltda., 28 y 20 , respectivamente. 
Tabla 2. Indicadores

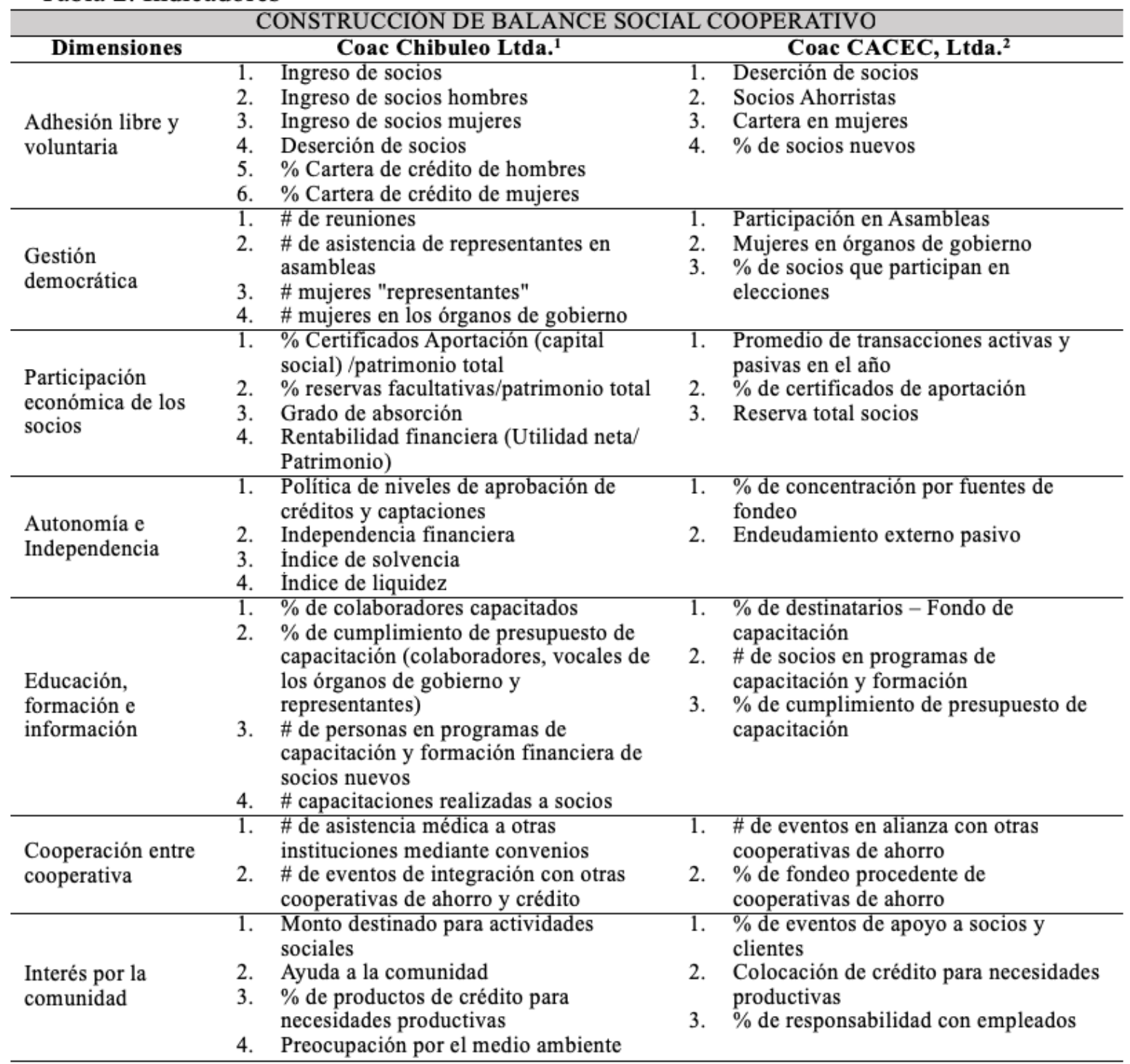

Fuente: Elaboración propia

En la estructura de Balance Social los indicadores permiten obtener información socioeconómica básica que cualquier institución cooperativa debe revelar a sus grupos de interés. Para ello se seleccionarán los indicadores más relevantes, ya que una información excesiva puede oscurecer lo que se pretende medir y obstaculizar su efectiva ejecución (Montes 2016).

En este sentido y considerando la flexibilidad del modelo basado en los principios cooperativos, la diferencia entre el número de indicadores evaluados de las dos cooperativas objeto de estudio consiste en el desarrollo de la misión y el enfoque de resultados esperados. Se considera que el sistema de indicadores creado para cada principio tie- ne capacidad suficiente para evaluar en qué medida la institución financiera desempeña el cumplimiento de la misión y que grado de correlación y desarrollo existe con los procesos de responsabilidad social en todas sus dimensiones como son económica, social y medioambiental (Ulla, Porrini \& Rolando 2007).

Según González y San Bartolomé (2008), la metodología para la medición de los indicadores del Balance Social Cooperativo incluye una escala valorativa que requiere al menos de tres niveles, con lo que se priorizan los planes de mejora para aquellas dimensiones cuyo promedio de valores asignados a sus indicadores están más alejados del ideal. 
Tabla 3. Resultados

\begin{tabular}{|c|c|c|c|c|}
\hline \multicolumn{5}{|c|}{ APLICACIÓN DE BALANCE SOCIAL COOPERATIVO } \\
\hline & Dimensiones & Misión & Coac Chibuleo Ltda. ${ }^{1}$ & Coac CACEC, Ltda. $^{2}$ \\
\hline P1 & Adhesión libre y voluntaria & 3,00 & 1,39 & 0,68 \\
\hline P2 & Gestión democrática & 3,00 & 2,25 & 1,83 \\
\hline P3 & $\begin{array}{l}\text { Participación económica de los } \\
\text { socios }\end{array}$ & 3,00 & 1,78 & 2,64 \\
\hline P4 & Autonomía e Independencia & 3,00 & 2,59 & 1,59 \\
\hline P5 & $\begin{array}{l}\text { Educación, formación e } \\
\text { información }\end{array}$ & 3,00 & 2,26 & 0,82 \\
\hline P6 & Cooperación entre cooperativa & 3,00 & 2,18 & 1,06 \\
\hline P7 & Interés por la comunidad & 3,00 & 1,53 & 1,55 \\
\hline
\end{tabular}

\section{Fuente: Elaboración propia}

Según la tabla 3 , se presenta el promedio por dimensiones (principios cooperativos) para las cooperativas motivo de estudio. En general los promedios de la cooperativa Chibuleo Ltda., son más altos de los de la CACEC Ltda., lo que determina un mejor desempeño social de la primera institución en relación a la segunda. Se evidencia que el principio 1 - P1 (adhesión libre y voluntaria), tiene el menor promedio de indicadores en los dos casos. Por otro lado, en Chibuleo Ltda., el promedio más alto corresponde al principio 4 - P4 (autonomía e independencia) ligado a parámetros financieros, mientras que en CACEC Ltda., el promedio más alto se re- porta en el principio 3 - P3 (participación económica de los socios) relacionado con el capital social o aporte de los socios a través de certificados de aportación y a las reservas que se alimentan de los excedentes acumulados.

La figura 2, señala la forma clásica de presentar los resultados del Balance Social Cooperativo. Muestra la comparación de los promedios calculados para las organizaciones. Los indicadores de la cooperativa Chibuleo Ltda., permiten promedios más cercanos al valor máximo o ideal, mientras que para CACEC Ltda., los promedios están significativamente más alejados.

Figura 2. Alineación

PROMEDIO DE INDICADORES POR DIMENSIÓN (PRINCIPIO COOPERATIVO)

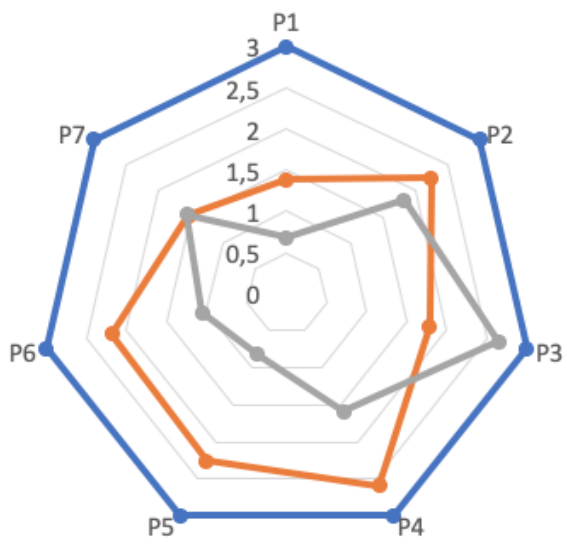

-Misión - Coac Chibuleo Ltda $=$ Coac CACEC, Ltda.

Fuente: Elaboración propia

回回回 回


Con los resultados obtenidos considerados como línea base, en cada caso se plantean planes de acción correctivos para mejorar los indicadores de los principios con menor valor para calcular nuevamente y verificar su evolución.

Una vez aplicados los planes de acción desarrollados en el primer semestre del año 2017, según la tabla 4 , se evidencian mejoras en el principio cooperativo al que se aplicaron las acciones correctivas.

En el caso de Chibuleo Ltda., el plan consistió en generar un producto crediticio con características más flexibles para los socios, lo que mejoró principalmente el indicador deserción de socios y por tanto el promedio en el principio 1 - P1 (adhesión libre y voluntaria) aumentó de 1,39 a 1,78.

En el caso de CACEC Ltda., el plan de ac- ción incluyó un programa de educación y entrenamiento a los socios con la consecuente mejora en varios indicadores. Se disminuyó el indicador deserción de socios logrando que el principio $1-\mathrm{P} 1$ (adhesión libre y voluntaria) pase de 0,68 a 1,37 ; además se incrementa el porcentaje de destinatarios; el porcentaje de socios en programas de capacitación y formación y el porcentaje de cumplimiento de presupuesto de capacitación lo que permite que el principio 5 - P5 (educación, formación e información) pase de 0,82 a 1,06 . De acuerdo a los reportes, se advierte además que el programa de capacitación tiene un efecto positivo en indicadores de gestión y financieros al mejorar el índice de morosidad que incide en los estados financieros.

Tabla 4. Mejoras obtenidas

\begin{tabular}{|c|c|c|c|c|c|}
\hline \multicolumn{6}{|c|}{ EVOLUCIONN BALANCE SOCIAL COOPERATIVO } \\
\hline \multirow{2}{*}{\multicolumn{2}{|c|}{ Dimensiones }} & \multicolumn{2}{|c|}{ Coac Chibuleo Ltda. ${ }^{1}$} & \multicolumn{2}{|c|}{ Coac CACEC, Ltda. $^{2}$} \\
\hline & & Lectura 0 & Lectura 1 & Lectura 0 & Lectura 1 (6 meses) \\
\hline P1 & Adhesión libre y voluntaria & 1,39 & 1,78 & 0,68 & 1,37 \\
\hline & $\begin{array}{l}\text { Educación, formación e } \\
\text { información }\end{array}$ & 2,56 & $\mathrm{n} / \mathrm{a}$ & 0,82 & 1,06 \\
\hline
\end{tabular}

Fuente: Elaboración propia a partir de Yumisaca y Coba (2017) y Mullo y Coba (2018).

La aplicación del Balance Social permitió la concesión de los objetivos planteados en cada cooperativa, aunque los mismos eran de diferente índole. Chibuleo Ltda., mejora sus indicadores de corte social y CACEC Ltda., obtiene mayor cupo financiamiento en función de mejorar los indicadores de desempeño social.

El sector cooperativo es una potente herramienta de cambio económico y social. Dónde no llegan poderes públicos, bancos, empresas, etc., las cooperativas desarrollan un amplio conocimiento de la realidad local. Están creadas a medida del contexto donde desarrollan su actividad (González, Arias \& San Bartolomé 2012). Entre sus funciones exógenas destacan ser catalizadoras de crisis financieras, proyectos negados por otras entidades, etc., así como proveer un amplio abanico de productos en la cobertura de necesidades locales. Pueden igualmente servir como medios de canalización de recursos públicos para el desarrollo e implementación de proyectos sociales y productivos en sus respectivos territorios (Junco, Benítez \& Crespo 2016). Según la Organización Internacional del Trabajo (2017:3)

Las cooperativas y otras empresas y organizaciones de la economía social y solidaria desempeñan un importante papel en la promoción de la iniciativa empresarial rural y del desarrollo de empresas, la creación de empleo y la prestación de protección social en las zonas rurales, así como en la representación y voz de los productores y trabajadores rurales.

Según la tabla 5, se muestra un resumen conceptual sobre los objetivos en la elaboración de un Balance Social. Se agrupan en seis dimensiones como son ética, social, legal, económica, organizacional y medioambiental. 
Tabla 5. Categorización

\begin{tabular}{|c|c|}
\hline & OBJETIVOS DEL BALANCE SOCIAL \\
\hline Dimensión & Alcance \\
\hline Ética & $\begin{array}{l}\text { 1. Toda actividad económica requiere responsabilidad social. } \\
\text { 2. Reforzar lealtad y compromiso de vinculados. } \\
\text { 3. Plasmar la identidad, valores, principios y objetivos de la cooperativa. } \\
\text { 4. Promover automatismos de control con el fin de identificar y erradicar procesos de } \\
\text { corrupción sea esta de carácter propio o exógeno. }\end{array}$ \\
\hline Social & $\begin{array}{l}\text { 1. Evaluación del buen gobierno cooperativo. } \\
\text { 2. Mostrar aportes sociales a grupos de interés y a la comunidad. } \\
\text { 3. Promover aspectos sociales, conocerse y reconocerse (identidad corporativa) con la } \\
\text { finalidad de analizar el cumplimiento de principios. } \\
\text { 4. Añadir valor social al económico. } \\
\text { 5. Compromiso social (comercio justo, comunidad y medio ambiente). } \\
\text { 6. Promociona la integración social de comunidades. }\end{array}$ \\
\hline Legal & $\begin{array}{l}\text { 1. Herramienta de comparación con el que establecer parámetros mínimos y mejoras. } \\
\text { 2. Información periódica, homogénea, automatizada y parametrizada. }\end{array}$ \\
\hline Económica & $\begin{array}{l}\text { 1. Permite evaluar la gestión cooperativa de manera diferente y alinear intereses. } \\
\text { 2. Evita manipulación y sesgo de información. } \\
\text { 3. Visibilizar no solo información contable. }\end{array}$ \\
\hline Organizacional & $\begin{array}{l}\text { 1. Herramienta de mejora continua en la calidad de la gestión. } \\
\text { 2. Facilidad en la comparación de entidades. } \\
\text { 3. Promueve interacción con otras entidades y organizaciones. } \\
\text { 4. Indicadores cuantitativos y cualitativos. } \\
\text { 5. Mejora toma de decisiones. } \\
\text { 6. Permite evaluar la gestión cooperativa de manera diferente y alinear intereses. } \\
\text { 7. Evita manipulación y sesgo de información. }\end{array}$ \\
\hline Medioambiental & $\begin{array}{l}\text { 1. Plasma la conservación de la tierra y el agua, los recursos genéticos, coexistencia } \\
\text { con el reino animal, degradación del medio ambiente, así como la promoción y } \\
\text { sostenibilidad de los mismos. } \\
\text { 2. Compromiso medioambiental a través de "compras verdes". }\end{array}$ \\
\hline
\end{tabular}

Fuente: Elaboración propia

El Balance Social Cooperativo es una eficiente herramienta de gestión para las cooperativas financieras, el caso de estudio demuestra que su aplicación no depende del tamaño de la organización ni del número de socios, pero además se valida en la práctica que es posible el cumplimiento de objetivos diversos tal como se demuestra en el análisis comparado de Chibuleo Ltda. y CACEC, Ltda., sin embargo para que sea una herramienta de gestión responsable, su construcción debe tener objetivos claramente definidos. 


\section{CONCLUSIONES}

La presente investigación analizó dos cooperativas de ahorro y crédito, mediante la utilización de la herramienta del balance social. Una vez comparados y examinados los datos, se observa el esfuerzo realizado por parte del sector cooperativo, así como de las instituciones de control y regulación (SEPS, Gobierno de Ecuador) a la hora de diseñar una herramienta de gestión social de carácter universal conocida como Balance Social. Los resultados del presente estudio, así como la revisión de la literatura existente demuestran carencias en su elaboración, coordinación, puesta en marcha y desarrollo ulterior. Se evidencia que la herramienta del balance social puede aplicarse a cooperativas de diferentes segmentos y misiones siendo los planes correctores de los indicadores (de cualquier índole) una alternativa adecuada a la mejorara del desempeño social cooperativo.

Damos como hecho probado la existencia de paralelismo entre los indicadores analizados en las dos cooperativas. En el caso de la Cooperativa Chibuleo Ltda. el principio 1-P1 (adhesión libre y voluntaria) se incrementó levemente su promedio ponderado por tanto se mejoró la retención de socios. En la Cooperativa CACEC Ltda. el principio 1-P1 (adhesión libre y voluntaria) aumentó significativamente hasta el punto de prácticamente duplicarse (pasando de 0,68 a 1,37 su valor ponderado) fidelizando igualmente a sus asociados. En el principio 5-P5 (educación, formación e información) se refleja un incremento considerable basado en programas de capacitación.

Cuantificar el mayor número de variables sin una correcta interpretación y contextualización las convierte en estériles, siendo necesario el establecimiento de medidas correctoras de carácter propositivo que sean parte de la planificación de las cooperativas reflejándose en indicadores financieros y de gestión bajo un modelo cooperativo con lineamientos sociales y solidarios.

La SEPS señala una serie de recomendacio- nes mientras que en la Constitución de Ecuador (CE) no se desarrollan plenamente estos preceptos más allá de ideas programáticas. ¿Se puede respetar y promover el medio ambiente desde el sector cooperativo mientras que la Constitución de Ecuador permite procesos de extractivismo medioambiental?, ¿tiene sentido recoger indicadores sociales o medioambientales cuando cumpliéndose $\mathrm{o}$ no, todas las cooperativas sufren la misma presión fiscal no discriminando a las cooperativas más sostenibles y con mejores procesos? Evidentemente tales circunstancias no son ni sociales ni promueven ningún tipo de cooperativismo que se considere ético y sostenible.

Se debe ir más allá a la hora de establecer el Balance Social, proponiendo diferencias entre segmentos y niveles. Existe la necesidad de otorgar una mayor calificación a cooperativas que promuevan mejoras por encima de las que obliga la ley. Cabe la necesidad de desarrollar una clara normativa que establezca necesidades a la hora de priorizar la contratación con administraciones públicas. Actualmente existen herramientas de evaluación suficientes, así como tecnología para regular y proponer incentivos relacionados con las cooperativas de ahorro y crédito. Destacan la implementación de medidas como el establecimiento de una menor presión fiscal, mayor acceso a financiación estatal, posibilidad de priorizar la contratación con la administración pública, etc.

Las cooperativas deben desarrollar un verdadero Balance Social sin subterfugios y obligatoriedades exógenas evitando la utilización de manera mañosa de esta herramienta como mero instrumento de marketing únicamente al servicio de su cuenta de resultados $\mathrm{y}$ de requerimientos normativos.

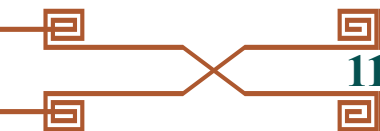




\section{REFERENCIAS BIBLIOGRÁFICAS}

Abela, J. (2002). Las técnicas de análisis de contenido: una revisión actualizada. Fundación Centro de Estudios Andaluces . Recuperado de http://public.centrodeestudiosandaluces.es/pdfs/S200103.pdf

Arias, F. (2012). El Proyecto de Investigación. Introducción a la metodología científica 5ta.

Arzbach, M., Durán, Á. \& Báez, B. (2010). Regulación y supervisión de cooperativas de ahorro $y$ crédito en América Latina y el Caribe. Cooperación Alemana de Cooperativas. Brasil.

Bastidas-Delgado, O. (2007). La autogestión como innovación social en las cooperativas. Venezuela: Red Universitaria de las Américas en Estudios Cooperativos y Asociativismo (RED Unircoop).

Castro, J. \& Hinestroza, R. (2000). Investigación Integral de Mercados:Unenfoqueparaelsiglo XXI.McGraw-Hill

Confederación Alemana de Cooperativas. (2010). Guía metodológica para la introducción de la Responsabilidad social y del Balance Social en Cooperativas de Ahorro y Crédito. Quito: DGRV.

Cooperativa de Ahorro y Crédito Chibuleo Ltda. (2018). Historia. Recuperado de http:// chibuleo.com/index.php/historia/

Cooperativa de Ahorro y Crédito de Educadores de Cotopaxi CACEC Ltda. (2018a). Balance General Septiembre 2018 . Recuperado de http://cacec.fin.ec/transparencia.php

Cooperativa de Ahorro y Crédito de Educadores de Cotopaxi CACEC Ltda. (2018b). Quienes Somos. CACEC. Recuperado de CACEC: $\quad$ http://cacec.fin.ec/somos.php

Cooperativas de las Américas ACI. (2018). Principios y Valores Cooperativos. Recuperado de https://www.aciamericas.coop/ Principios-y-Valores-Cooperativos-4456

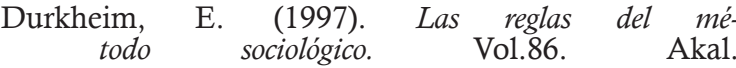

Fernández, L., Geba, N., Montes, V. \& Schaposnik, C. (1998). Balance Social cooperativo integral. Cuaderno Serie de Investigación, 57.

González, L. \& San Bartolomé, J. (2008). Balance Social Cooperativo: Una construcción en Construcción. Argentina: Centro de Acción, Desarrollo e Investigación en Cooperativas y Mutuales.

González, L., Arias, N. \& San Bartolomé, J. (2012). El balance social cooperativo: Una herramienta necesaria para la gestión cooperativa. En ACIAméricas (Ed.). Jornadas 2012, Propuestas del cooperativismo. Rosario, Argentina.

Junco, O., Benítez, L. \& Crespo, G. (2016). El cooperativismo en la economía social e instrumento de participación ciudadana: necesidad de inserción en la producción bananera ecuatoriana. Cooperativismo y desarrollo, 4(2), 131-138.

León, A., Fleitas, N., Rivera, D., Nariño, A., Alonso, A. \& Moya, J. (2011). Estudio de la construcción de índices integrales para el apoyo al Control de Gestión Empresarial. Enfoque UTE, 2(1), 1-38.
Ley de Economía Popular y Solidaria y del Sistema Financiero Popular y Solidario. (2011). http://www.seps.gob.ec. Recuperado de http://www.seps.gob.ec/interna-npe?760

Lucena, H., Freitez, N. \& Hernández, A. (2007). Cooperativas, empresas, estado y sindicatos. Una vinculación necesaria. Universidad de Carabobo. Universidad Centroccidental Lisandro Alvarado.

Marradi, A., Archenti, N. \& Piovani, J. (2007). Metodología de las ciencias sociales. Buenos Aires: Emecé.

Martínez, G. \& Bialakowsky, A. (1984). El balance social en las cooperativas: evaluación sistemática del impacto social. Buenos Aires: Colegio de Graduados en Cooperativismo y Mutualismo.

Mathiyazhagan, K., Govindan, K., NoorulHaq, A. \& Geng, Y. (2013). An ISM approach for the barrier analysis in implementing green supply chain management. Journal of Cleaner Production, 47, 283-297.

Montes, V. (2016). ¿Para qué el balance social? Una experiencia de aplicación del Modelo de Balance Social Cooperativo Integral en cooperativas ecuatorianas. En Economía Solidaria. Historias y prácticas de su fortalecimiento (pp. 199-223). Quito: Publiasesores.

Mullo, N. \& Coba, E. (2018). La Responsabilidad Social Empresarial como herramienta para mejorar la fuente de financiamiento para la Cooperetiva de Ahorro y Crédito CACEC Ltda. de la ciudad Latacunga. Ambato: Unversidad Tecológica Indoamérica.

Nevado, D. (1999). Control de gestión social: la auditoría de los recursos humanos. Cuenca: Universidad de Castilla La Mancha.

Ocampo, S., Perdomo-Ortiz, J. \& Castaño, L. (2014). El concepto de consumo socialmente responsable y su medición. Una revisión de la literatura. Estudios Gerenciales, 30(132), 287-300.

Organización Internacional del Trabajo. (2017). Fortalecimiento del desarrollo local en las zonas rurales mediante cooperativas $y$ otras empresas $y$ organizaciones de la economía social y solidaria. Recuperado de https://www.ilo.org/ wcmsp5/groups/public/---ed_emp/---emp_policy/documents/publication/wcms_437229.pdf

Organización Internacional del Trabajo. (2018). Cooperativas. Recuperado de http://www.ilo.org/ global/topics/cooperatives/lang--es/index.htm

Páez, J. (2013). Importancia del Balance Social para las organizaciones de la economía popular y solidaria: Desarrollo metodológico de la SEPS. En Intendencia de Estadísticas, Estudios y Normas. Intendencia de Estadísticas, Estudios y Normas (ed.). Estudios sobre Economía Popular y Solidaria, 145-200. Quito:Ecuador.

Pazos, C., Guamaní, A. \& Égüez, S. (2018). Desarrollo del sector económico popular y solidario en Ecuador: antes y después de la creación de la Superintendencia de Economía Popular y Solidaria. En La Economía Popular y Solidaria. un modelo viable de desarrollo económico. VII Jornadas de supervisión de la Economía Popular y Solidaria. Documentos de trabajo 2018 (pp. 25-49). Quito: Superintendencia de Economía Popular y Solidaria. Recuperado de http://www.seps. gob.ec/documents/20181/26626/Documen- 


\section{Unach}

REVISTA CHAKIÑAN, 2019, N․7, ABRIL, (104-117)

tos $\% 20$ de $\% 20$ trabajo $\% 20$ de $\% 20$ VII $\% 20$ jornadas.pdf/82684fa0-e96f-47c8-b8fc-c6298a4d3ec5

Ramos, C. (2017). Los paradigmas de la investigación científica. Avances en Psicología, 23(1), 9-17.

Sartori, G. \& Morlino, L. (1999). La comparación en las ciencias sociales. Madrid: Alianza Editorial.

Schlusberg, M. (1969). Corporate legitimacy and social responsibility: The role of law. $\mathrm{Ca}$ lifornia Management Review, 12(1), 65-76.

Sheldon, O. (1923). The Philosophy of Management. Edición americana.

Superintedencia de Economía Social y Solidaria. (2017). Boletín Financiero, Productos estadísticos. Recuperado de http://www.seps.gob ec/estadistica?boletin-financiero-sf-y-snf

Superintendencia de la Economía Popular y Solidaria. (2018a). Balance social cooperativo. Recuperado de http://www.seps. gob.ec/documents/20181/26626/ Presentacio\% C C \% $81 \mathrm{n} \% 20 \mathrm{bal}$ an ce $\% 20$ social\%20 cooperativo_a.pdf/ e2b49430-9a5d-43a9-a 8c4-d909171c45b2

Superintendencia de la Economía Popular y Solidaria. (04 de febrero de 2018b). Ecuador tiene un total de 887 cooperativas de ahorro y crédito. Recuperado de: http://www. seps gob ec/noticia?ecuador-tiene-un-total-de-887-cooperativas-de-ahorro-y-credito

Superintendencia de Economía Popular y Solidaria. (2019). Boletin Financiero Cooperativo - Segmento 1, 2018. Recuperado de http://www. seps.gob.ec/documents/20181/716248/ Boletin_financiero_Ene18_Dic18_S1_r.xls$\mathrm{m} / 0 \mathrm{c} 29766 \mathrm{f}-73 \mathrm{~d} 6-4 \mathrm{c} 37-9739-\mathrm{a} 8 \mathrm{fb} 6 \mathrm{e} 9 \mathrm{f} 8 \mathrm{f} 97$

Ulla, L., Porrini, M. \& Rolando, A. (2007). Indicadores de responsabilidad social para cooperativas de usuariós. Córdoba, Argentina: Estudio Artwork.

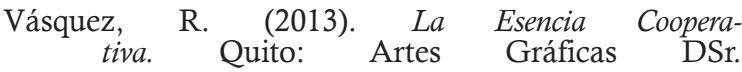

Vivero, G. (08 de junio de 2015). Las cooperativas crecen $y$ se adaptan a nuevas regulaciones. $\mathrm{Re}-$ cuperado de http://m.revistalideres.ec/articulo/lideres/cooperativas-ecuador-crecimiento-adaptan-nuevas.html no está habilitado

White, H. (1992). El contenido de la forma: narrativa, discurso y representación histórica. Paidós Ibérica.

Yumisaca, S. \& Coba, E. (2017). La responsabilidad social en el marco de los principios del cooperativismo. caso de estudio Cooperativa de Ahorro y Crédito Chibuleo ltda, de la ciudad de ambato. Ambato: Universidad Tecnológica Indoamérica.

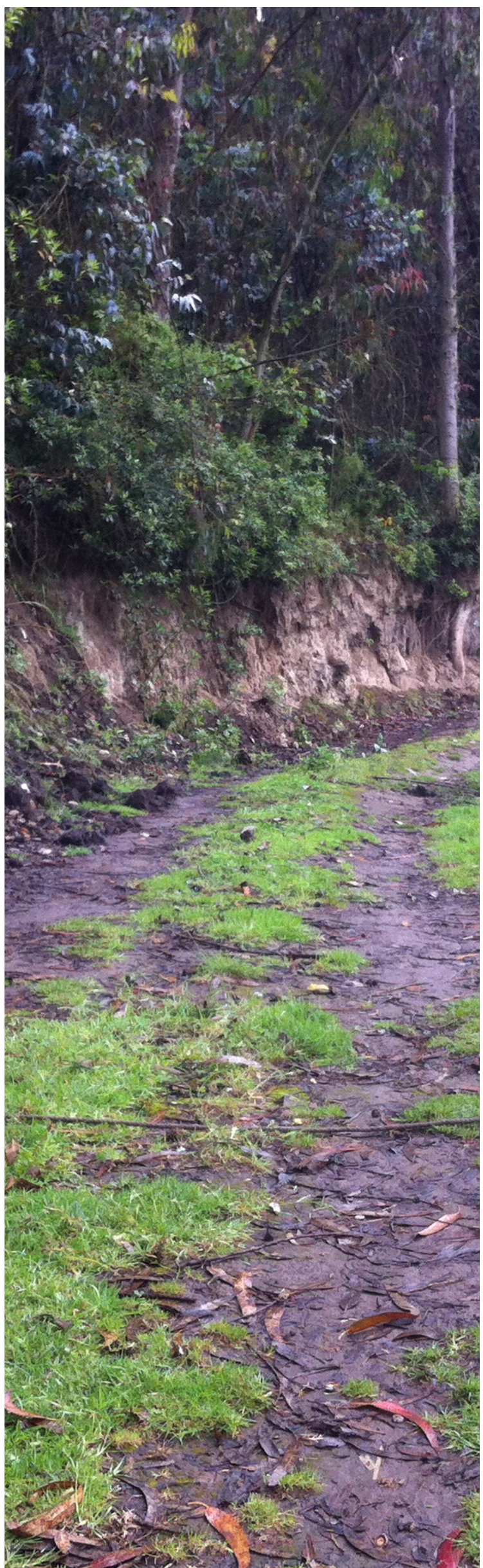

